\title{
Labor Heterogeneity and Asset Prices: the Importance of Skilled Labor
}

\author{
Frederico Belo* Xiaoji $\operatorname{Lin}^{\dagger}$
}

February 2014

\begin{abstract}
Heterogeneity in the composition of the labor force affects asset prices in the cross section. We combine a model of labor heterogeneity with a neoclassical q-theory model with labor adjustment costs and show that the negative expected return-hiring rate relation documented in previous studies should be steeper in industries with higher labor adjustment costs. Empirically, using a novel industry level measure of labor skills as a proxy for the size of labor adjustment costs, we show that the negative expected return-hiring rate relation is two times larger among industries with higher labor skills than in industries with lower labor skills.
\end{abstract}

JEL Classification: E22, E23, E44, G12

Keywords: Skill Premium, Labor Hiring, Investment, Stock Return Predictability, CrossSectional Asset Pricing, $q$-theory

\footnotetext{
${ }^{*}$ First version: September 2012. Corresponding author. Department of Finance, University of Minnesota, and NBER. Address: 321 19th Avenue South, Minneapolis MN 55455. Office: 3-233. e-mail: fbelo@umn.edu

${ }^{\dagger}$ Department of Finance, Fisher College of Business, The Ohio State University. Address: 2100 Neil Avenue, Columbus OH 43210. e-mail:lin_1376@fisher.osu.edu
} 


\section{Introduction}

Labor is not a homogenous input in firms' production technology. There is a large heterogeneity in the labor force - for example, a high skilled worker (e.g., an engineer) is a different input from a low skilled worker (e.g., a janitor). While low skilled workers execute routine tasks and are relatively easier to hire and replace, high skilled workers execute complex tasks and are costly to hire and replace. Given their different nature, workers with different levels of skills play different roles in firms' production processes, and thus contribute differently for the properties of firms' cash flows. In this paper, we examine the impact of this specific form of labor force heterogeneity- differences in average labor skills - on firms' value and risk using data on the cross section of U.S. publicly traded firms. We show that labor heterogeneity across industries affect asset prices in financial markets in important ways.

To establish the theoretical link between labor skills and asset prices, we combine a standard model of labor heterogeneity with a standard q-theory model of investment. Following the approach in Acemoglu (2002), we assume that firms produce output with two types of workers, which we refer to as skilled and unskilled workers. ${ }^{1}$ Treating the firm's hiring decision of skilled and unskilled workers as analogous to an investment decision, we specify hiring and firing to be costly, which we model through an adjustment cost function. ${ }^{2}$ The key difference between skilled and unskilled workers that we emphasize in the model is that it is more costly to hire and fire a skilled worker than an unskilled worker. Skilled workers are also more productive and charge higher wages in equilibrium to capture the obvious fundamental distinctive features of the two labor inputs. Through comparative statics, we use the theoretical model to obtain several empirical predictions that we test in

\footnotetext{
${ }^{1}$ This approach is standard. See also Kydland (1984), Katz and Murphy (1992), Acemoglu and Autor (2011), among many others.

${ }^{2}$ The idea that both labor and capital are costly to adjust is an old one. See, for example, on capital Lucas (1967) and on capital and labor, Nidiri and Rosen (1969). More recently, the search and matching models of Diamond (1982), Mortensen (1981), and Pissarides (1985) emphasize the existence of frictions in the labor markets that prevent firms from costlessly adjust its labor stock.
} 
the data.

Consistent with previous studies, the model predicts a negative relation between the hiring rate and stock returns when labor is costly to adjust. More important, the model makes the novel prediction that the negative expected return-hiring relation is steeper in industries with higher labor adjustment costs of skilled workers. This result is intuitive. From standard q-theory with labor adjustment costs, hiring is high when expected future cash flows from labor are high, or when discount rates (expected stock returns) are low. The higher the labor adjustment costs are, the less elastically hiring responds to changes in the discount rate. Thus, when adjustment costs are higher, a given magnitude change in the hiring rate corresponds to a higher magnitude change in the discount rate. Li and Zhang (2010) obtain a similar result in the context of a model in which firms face different adjustment costs of physical capital. We show that a similar result holds for the relationship between hiring and the size of labor adjustment costs, and in a setup with factor input heterogeneity.

We test the model's main prediction by studying the relationship between hiring and stock returns across industries with different average levels of labor skills. Thus, we interpret the industry average level of labor skill as informative about the magnitude of labor adjustment costs in a given industry. This interpretation is consistent with previous studies. According to the labor adjustment cost estimates surveyed in Hamermesh (1993), it is significantly more costly to adjust a high skilled worker than a low skilled worker. For example, it is more costly to replace a mechanical engineer than a janitor. This is intuitive because the worker screening, selection, and hiring process is more difficult for jobs that require very specialized skills since these skills are not easy to identify. ${ }^{3}$ In addition, the training of a high skilled worker is more costly because of the higher complexity of the tasks that the worker has to perform. Furthermore, high skilled workers posses firm-specific capital or firm-specific relationship with the firm, which makes it particularly costly for firms to fire skilled workers

\footnotetext{
${ }^{3}$ See, for example, Cappelli and Wilk (1997), Murnane and Levy (1996), and Acemoglu (2001).
} 
because this would destroy firm-specific capital. This makes high skilled workers appear to have higher firing costs as well (see Caballero 2007).

Following Donangelo (2012), we use data from JobZones at O*Net from 1988 to 2010, and we classify industries as low or high skilled labor industries using information on the number of years required for a typical worker in a given industry to perform the regular tasks associated with the job. We interpret more years of preparation in a given industry as evidence of the existence of relatively higher labor skills in that industry.

Our empirical results provide support for the model's main prediction. The negative expected return-hiring relation is much steeper for firms in industries with highly skilled labor. The hiring return spread, the empirical fact that firms with relatively higher hiring rates in the cross section tend to have relatively lower future stock returns, is considerably larger in industries with high skilled labor. In low skilled labor industries, the hiring return spread is about $3 \%$ per annum, and this value is only 1.4 standard errors from zero. In high skilled labor industries, the hiring return spread is about $7 \%$ per annum, and this value is more than 1.8 standard errors from zero. Thus, the hiring return spread is about two times larger among industries with higher labor skills than in industries with lower labor skills.

The model's main prediction also holds when we control for the well documented link between firms' investment and future stock returns (e.g. Cochrane, 1991, Jermann, 1998, and many other subsequent studies). Controlling for the firms' investment rate, the hiring return spread is only $1.6 \%$ per annum in low skilled labor industries, and this value is only 1 standard error from zero. In high skilled labor industries, the hiring return spread is $4.1 \%$ per annum after controlling for the firm's investment rate, and this value is more than 2 standard errors from zero. The magnitude of these empirical links is economically large. In firm-level stock return predictability regressions that control for firm and time fixed effects, we find that among low skill labor industries, a one standard deviation increase in the firm's hiring rate is associated with a $2.3 \%$ decrease in the firm's annual stock return, controlling for the firm's investment rate. In high skill labor industries, a one standard deviation increase 
in the firm hiring rate is associated with a $5.4 \%$ decrease in the firm's annual stock return, controlling for the firm's investment rate. That is, in these predictability regressions, the hiring rate negative slope coefficient in high labor skill industries is more than twice the (absolute) value of the hiring rate negative slope coefficient in low labor skill industries.

We also document a unconditional labor skill return spread among small firms, a finding that is consistent with the theoretical model. Firms in high-skilled industries earns on average about $9.9 \%$ per annum higher returns than firms in low skilled industries when we use equalweighted portfolio returns. But we find no significant difference, only about $2.3 \%$ per annum, when the returns are value-weighted, even after accounting for the disproportionate effect of mega caps on the returns of value-weighted portfolios. The fact that average returns among firms with more skilled labor are higher at least for small firms, is also consistent with the hypothesis that the characteristic of the labor force has an important impact on the overall unconditional level of firms' risk. ${ }^{4}$ Within the simple labor-augmented q-theory investment-based model that we consider here, more skilled labor is risky because it is more costly to adjust. In turn, this affects the ability of the firm to respond to aggregate shocks, thus increasing its overall risk.

Naturally, the impact of differences in the average level of labor skills on firms' performance varies in many other dimensions that we do not consider here. The skills of the labor force affect how firms respond to aggregate shocks, in particular, it affects the firms' ability to adapt to changes in the economic environment. Some of these differences operate through different mechanisms that go beyond the simple cost of hiring and firing workers. Incorporating all the differential effect of labor skills on firms' output at the same time in one model is an important but complex task. Thus, our results highlight the role of one specific difference: incorporating differences in labor adjustment costs between skilled and unskilled workers in an otherwise standard q-theory model generates differences in risk

\footnotetext{
${ }^{4}$ We rationalize this difference in the return spread across firms with different size as a result of the properties of the firms production technology, in particular, due to a combination of decreasing returns to scale in the operating profit function and constant returns to scale in the adjustment cost function.
} 
premia across low and high skilled labor firms that is consistent with the empirical links that we document here. This results suggests that differences in the adjustment costs of low and high skilled workers is an important channel through which labor heterogeneity affects asset prices.

\section{Related Literature}

The work in this paper is related to several strands of literature. The existence and importance of labor heterogeneity is well established, and it is at the heart of the overall labor economics literature. In this paper, we examine the implications of a specific form of labor heterogeneity (differences in labor skills) for asset prices, thus helping to bring together the labor economics and asset pricing literatures. Our analysis is closely related to Gourio (2007), Merz and Yashiv (2007), Bloom (2009), and Belo, Lin and Bazdresch (2012), who emphasize the importance of labor frictions to understand asset prices. ${ }^{5}$ None of these papers explicitly consider heterogeneity in the labor force as we have here. Our focus on labor heterogeneity is also related to the work by Lustig, Syverson, and Van Nieuwerburgh (2011), Eisfeldt and Papanikolaou (2012), and Donangelo (2012). Lustig, Syverson, and Van Nieuwerburgh (2011) show that technological change starting from 1970s stimulates the accumulation of firms' organizational capital which in turn lead to the secular change in the U.S. labor market reallocations. By constructing a firm level measure of organizational capital, Eisfeldt and Papanikolaou (2012) show that firms with more organizational capital are riskier than firms with less organizational capital. Because organizational capital is embodied in the labor force, their findings show that the characteristics of the labor force have an impact on firms' risk, a finding that is consistent with the main findings that we report here. Donangelo (2012) shows that differences in labor mobility, i.e. the flexibility of workers to walk away from employers in response to better opportunities, leads to differences in risk premiums in the cross section. Our analysis focuses on a different labor characteristic,

\footnotetext{
${ }^{5}$ See also Uhlig (2007) for an analysis of the link between labor market frictions and asset prices at the aggregate level. Danthine and Donaldson (2002) is the first study to show that operating leverage resulting from frictions in the determination of the wage rate magnifies the risk premium of equity returns at the aggregate level.
} 
skilled labor.

A sizeable empirical literature on asset pricing explores the predictability of firm characteristics for stock returns in the cross-section of stock returns (Fama and French, 2008, provide a survey of this literature). Our work links firm characteristics to the characteristics of the labor force (skilled labor). Our approach is also closely related to the investmentbased asset pricing literature that emerged from the q-theory of investment. Barring a few exceptions, labor is typically ignored in the q-theory literature, or it does not affect asset prices because it can be costlessly adjusted. More important, even when labor is included, labor is assumed to be an homogenous input across firms. We thus depart from this literature by incorporating labor heterogeneity in a simple $q$-theory model. Within this literature, our theoretical analysis is also related to the approach in Li and Zhang (2010) who study the link between differences in the magnitude of investment frictions across firms and risk premiums. Our work is different because we focus on differences in hiring frictions across firms, which we relate to the characteristics of the labor force.

Building on Bloom (2009) and Belo, Lin, and Bazdresch (2012), in a contemporaneous paper, Ochoa (2012) also documents that firms in high skilled labor industries have higher returns than firms in low skilled labor industries using a similar labor skill measure, consistent with some of the empirical results reported here for the skill return spread. In contrast with Ochoa (2012), our main empirical analysis focuses on the negative hiring-expected return spread and its variation across industries with different labor skills levels. Focusing on this hiring-return spread is similar to the approach in the large q-theory of investment literature which focuses on the negative investment-expected return spread relationship.

Our analysis is influenced by earlier studies which emphasize the importance of human capital, a characteristic of the labor force that is closely related to labor skills, for understanding asset prices. References on the relationship between human capital and asset returns go as far back as Mayers (1972) and Fama and Schwert (1977). Subsequent studies document strong correlations between stock market returns and labor market variables. 
Examples include Campbell (1996), Jagannathan and Wang (1996), Asness, Porter and Stevens (2000), Boyd, Hu and Jagannathan (2005), Lustig and Van Nieuwerburgh (2008), Santos and Veronesi (2006), among many others. We focus on firm level labor variables and we interpret the empirical findings through the lens of a production-based approach to asset pricing, thus focusing on the characteristics of the firms' technologies. Our analysis is also different because we focus on the impact of heterogeneity in the labor force on asset prices.

Finally, our work is related to the literature on labor demand and investment which investigates the importance of capital and labor adjustment costs to explain investment and hiring dynamics. ${ }^{6}$ We provide indirect evidence that rents arising from labor adjustment costs can be considerable, by showing that input adjustment costs generates stock return predictability at the firm level, which we confirm in the data. Moreover, our analysis provides supports for the hypothesis that the return predictability is driven in part by labor adjustment costs, by showing a close link between the variation in predictability across firms with different average labor skills, which we link to differences in labor adjustment costs.

The paper proceeds as follows. Section 2 proposes a simple model with labor heterogeneity and labor adjustment costs to develops the testable predictions. Section 3 describes the asset prices, accounting, and labor market data used in our empirical tests. Section 4 presents our empirical results. Finally, Section 5 concludes.

\section{Hypothesis development}

To link skilled labor, hiring decisions, and equilibrium risk premiums, we combine a standard model of labor heterogeneity with a standard q-theory model of investment. Following Acemoglu (2002), we assume firms produce output with two types of workers, which we refer to as skilled and unskilled workers. We then assume that hiring and firing workers is subject to adjustment costs. The key difference between skilled and unskilled workers is that it is

\footnotetext{
${ }^{6}$ Hamermesh and Pfann (1996) and Bond and Van Reenen (2007) provide a survey of the literature. Hamermesh (1993) reviews a set of direct estimates of the costs of adjusting labor.
} 
more costly to hire and fire a skilled worker than an unskilled worker. Skilled workers are also more productive and thus charge higher wages in equilibrium.

In this section, we solve the problem of a cross-section of heterogeneous firms in a given industry, and we perform several comparative statics exercises to obtain testable predictions that we then test in the cross section of U.S. publicly traded firms. Firms in a given industry are heterogeneous in their firm-specific total factor productivity (TFP, or Solow residual). What distinguishes firms across industries is that the level of skills of the skilled workers varies across industries, a fact that we capture here by allowing for a different size of the skilled labor adjustment cost parameter. Consistent with empirical evidence, it is more costly to hire or fire a more skilled worker - for example, it is more costly to replace a mechanical engineer than a janitor. By performing simple comparative statics exercises with respect to the key labor adjustment cost parameter, the model that we consider here allows us to obtain testing hypothesis and organize the empirical analysis in a simple manner.

\subsection{The model}

Following Acemoglu (2002), we assume that firms hire skilled labor $N_{i, t}^{s}$ and unskilled labor $N_{i, t}^{u}$ to produce a homogeneous good $Y_{i, t}$ with a constant elasticity of substitution (CES) production technology ( $i$ denotes the firm index):

$$
Y_{i, t}=Z_{i, t}\left[\alpha^{s}\left(X_{t} N_{i, t}^{s}\right)^{\frac{\phi-1}{\phi}}+\left(1-\alpha^{s}\right)\left(N_{i, t}^{u}\right)^{\frac{\phi-1}{\phi}}\right]^{\frac{\phi \theta}{\phi-1}}
$$

in which $X_{t}$ is the aggregate factor augmenting productivity levels, $Z_{i, t}$ is the firm specific productivity, and $\alpha^{s}$ controls the share of skilled labor in output production. To simplify the analysis, we assume the factor productivity of unskilled labor is constant and is normalized to 1 . To capture the fact that skilled workers are more productive than unskilled workers, we assume the long run average level of the factor productivity associated with skilled labor, $X_{t}$, is bigger than 1 . The elasticity of substitution between $N_{i, t}^{s}$ and $N_{i, t}^{u}$ is $\phi \in[0, \infty)$, and $\theta$ 
is the returns to scale parameter. The CES production function in Eq. (1) contains several well-known production functions as special cases, depending on the value of parameter $\phi$. For instance, when $\phi \rightarrow \infty$, high skill and low skill workers are perfect substitutes (and thus there is only one skill, which $N_{i, t}^{s}$ and $N_{i, t}^{u}$ workers possess in different quantities); when $\phi \rightarrow 1$, $Y_{i, t}$ is the Cobb-Douglas technology; when $\phi \rightarrow 0, Y_{i, t}$ reduces to the Leontief technology in which output can be produced only by using high skill and low skill workers in fixed portions.

In the rest of the paper, we drop the firm index $i$ when no confusion results.

The law of motion for skilled labor is given by

$$
N_{t+1}^{s}=\left(1-\delta^{s}\right) N_{t}^{s}+H_{t}^{s}
$$

where $H_{t}^{s}$ is gross skilled labor hiring, and $\delta^{s}$ is the skilled labor separation rate, the rate at which skilled workers leave the firm. Similarly, the law of motion for unskilled labor is given by

$$
N_{t+1}^{u}=\left(1-\delta^{u}\right) N_{t}^{u}+H_{t}^{u}
$$

where $H_{t}^{u}$ is gross unskilled labor hiring, and $\delta^{u}$ is the unskilled labor separation rate.

Following Merz and Yashiv (2007), Bloom (2009), and Belo, Lin, and Bazdresch (2012), labor hiring is subject to adjustment costs. We specify the following adjustment cost function:

$$
C_{t}^{\mathrm{adj}}=\frac{c^{s}}{2}\left(\frac{H_{t}^{s}}{N_{t}^{s}}\right)^{2} N_{t}^{s}+\frac{c^{u}}{2}\left(\frac{H_{t}^{u}}{N_{t}^{u}}\right)^{2} N_{t}^{u}
$$

in which $c^{s}>c^{u} \geq 0$ are the adjustment cost parameters for skilled and unskilled labor, respectively. We assume $c^{s}>c^{u}$ to capture the fact that skilled labor is more costly to adjust than unskilled labor. This is the key parameter in all our analysis. According to this specification, labor adjustment costs are convex. The labor adjustment costs include training and screening of new workers, advertising of job positions, as well as output that is lost through time taken to readjust the schedule and pattern of production. The convex labor adjustment costs capture the fact that the adjustment costs may be related to the rate 
of adjustment due to higher costs for more rapid changes. All of these costs are higher for more skilled workers, consistent with the empirical results in Hamermesh (1993).

We assume firms are purely equity financed. As such, dividend is given by:

$$
D_{t}=Y_{t}-W_{t}^{s} N_{t}^{s}-W_{t}^{u} N_{t}^{u}-C_{t}^{\text {adj }}
$$

where $W_{t}^{s}$ and $W_{t}^{u}$ are the wage rate for skilled and unskilled workers, respectively, which are correlated with the aggregate productivity process.

The firm's one period equity return is defined as

$$
R_{t+1}^{e} \equiv \frac{P_{t+1}+D_{t+1}}{P_{t}}
$$

in which $P_{t}$ is the ex dividend stock price.

Define the vector of state variables as $\Theta_{t}=\left(N_{t}^{s}, N_{t}^{u}, X_{t}, Z_{i, t} ; W_{t}^{s}, W_{t}^{u}\right)$. The firm makes skilled labor and unskilled labor hiring (firing) decisions to maximize the firm's market value of equity subject to equations (2), (3) and (5):

$$
V\left(\Theta_{t}\right)=\max _{H_{t+j}^{s}, H_{t+j}^{u}} \mathbb{E}_{t} \sum_{j=0}^{\infty} M_{t, t+j} D_{t+j}
$$

where $M_{t, t+1}$ is the stochastic discount factor from date $t$ to date $t+1$ that is correlated with the aggregate productivity .

In general, the model does not have an analytical solution. Under some assumptions, however, we can easily link the equilibrium firm value and equilibrium stock return directly to the firm's hiring rate, which is the focus of our empirical analysis. We state this link explicitly in Proposition 1.

Proposition 1 The ex-dividend stock price, $P_{t}$, equals the sum of the market value of the installed skilled and unskilled labor stock when both the production function and the adjustment cost function are homogeneous of degree one $(\theta=1)$. The stock (equity) return 
is a weighted average of the skilled labor and unskilled labor hire returns:

$$
\begin{aligned}
P_{t} & =Q_{t}^{s} N_{t+1}^{s}+Q_{t}^{u} N_{t+1}^{u} \\
R_{t+1}^{e} & =\frac{Q_{t}^{s} N_{t+1}^{s}}{P_{t}} R_{t+1}^{s}+\frac{Q_{t}^{u} N_{t+1}^{u}}{P_{t}} R_{t+1}^{u}
\end{aligned}
$$

where

$$
\begin{aligned}
Q_{t}^{s} & =c^{s} \frac{H_{t}^{s}}{N_{t}^{s}}, \quad Q_{t}^{u}=c^{u} \frac{H_{t}^{u}}{N_{t}^{u}} \\
R_{t+1}^{s} & =\frac{\frac{\partial Y_{t+1}}{\partial N_{t+1}^{s}}-W_{t+1}^{s}+\frac{c^{s}}{2}\left(\frac{H_{t+1}^{s}}{N_{t+1}^{s}}\right)^{2}+\left(1-\delta^{s}\right) c^{s} \frac{H_{t+1}^{s}}{N_{t+1}^{s}}}{c^{s} \frac{H_{t}^{s}}{N_{t}^{s}}} \\
R_{t+1}^{u} & =\frac{\frac{\partial Y_{t+1}}{\partial N_{t+1}^{u}}-W_{t+1}^{u}+\frac{c^{u}}{2}\left(\frac{H_{t+1}^{u}}{N_{t+1}^{u}}\right)^{2}+\left(1-\delta^{u}\right) c^{u} \frac{H_{t+1}^{u}}{N_{t+1}^{u}}}{c^{u} \frac{H_{t}^{u}}{N_{t}^{u}}}
\end{aligned}
$$

with $\frac{\partial Y_{t+1}}{\partial N_{t+1}^{s}}$ and $\frac{\partial Y_{t+1}}{\partial N_{t+1}^{u}}$ are the partial derivatives of $Y_{t+1}$ w.r.t. to $N_{t+1}^{s}$ and $N_{t+1}^{u}$, $Q_{t}^{s}$ and $Q_{t}^{u}$ the prices (Lagrange multipliers) of skilled and unskilled labor, and $R_{t+1}^{s}$ and $R_{t+1}^{u}$ are the skilled labor hiring and unskilled labor hiring returns, respectively.

Proof. See Appendix.

Under these assumptions, the production function and the adjustment cost function are both homogeneous of degree one. Then the market value decomposition follows from the standard Hayashi's (1982) result extended to a multi factor inputs setting.

Equation (9) links the firm's equity returns to the firm's hiring rates in the two labor inputs. Our main goal is to understand the relationship between risk premiums and (total) hiring rates across industries with different degrees of skilled labor, which we can capture in the model as differences in the adjustment cost parameter of skilled labor, $c^{s}$. In particular, we want to use the model to understand the sensitivity of the firm's risk premium to the firms' total (skilled and unskilled) hiring rate across industries with different degrees of skilled labor, that is, we want to compute the following derivative, $d\left[\frac{d E\left[R_{t+1}^{e}\right]}{d\left(H_{t} / N_{t}\right)}\right] / d c^{s}$, in which $H_{t} / N_{t}$ is the total hiring rate of skilled and unskilled workers $\left(H_{t}=H_{t}^{s}+H_{t}^{u}\right.$, divided by the total 
labor stock, $N_{t}=N_{t}^{s}+N_{t}^{u}$ ). We focus on the total hiring rate because that is the information that we have in the data (as we discuss below, we do not use separate industry-level data for skilled and unskilled workers)

Unfortunately, to examine the previous theoretical relationship in the model, we cannot use simple partial derivatives on equation (9) with respect to the skill labor adjustment cost parameter $c^{s}$. Because all variables of interest, including the firms' hiring rate and equilibrium risk premium, are endogenously determined in the model, the optimal policy functions change as the parameters of the model change. As such, to obtain testable predictions regarding the firms sensitivity of equilibrium expected returns to the hiring rate, we solve the baseline model numerically.

\subsection{Stochastic processes}

Given our focus on the production side of the economy, we directly specify the stochastic discount factor without explicitly modeling the consumer's problem as in Zhang (2005), as well as the equilibrium wage rate processes, as in Belo, Lin, and Bazdresch (2012). The wage rate processes for skilled and unskilled workers are given by

$$
\begin{aligned}
& W_{t}^{s}=\lambda^{s} \exp \left(\eta^{s}\left(\log X_{t}-\log \bar{X}\right)\right), \\
& W_{t}^{u}=\lambda^{u} \exp \left(\eta^{u}\left(\log X_{t}-\log \bar{X}\right)\right),
\end{aligned}
$$

in which the factor augmenting productivity process $X_{t+1}$ are given by

$$
\log X_{t+1}=\left(1-\rho_{X}\right) \log \bar{X}+\rho \log X_{t}+\sigma_{X} \epsilon_{t+1}^{X}
$$

In the previous equation, $\epsilon_{t+1}^{X}$ is an independently and identically distributed (i.i.d.)

standard normal shocks, and $\bar{X}, \rho_{X}$, and $\sigma_{X}$ are the long-run average level, persistence, and conditional volatility of the aggregate skilled productivity process, respectively. Firm-specific 
productivity follows an $\mathrm{AR}(1)$ process:

$$
\log Z_{i, t+1}=\rho_{Z} \log Z_{i, t}+\sigma_{Z} \epsilon_{t+1}^{Z},
$$

where $\epsilon_{t+1}^{Z}$ is an i.i.d standard normal shock that is uncorrelated across all firms in the

economy, and $\epsilon_{t+1}^{X}$ is independent of $\epsilon_{t+1}^{Z}$ for each firm. In the model, the aggregate productivity shock is the driving force of economic fluctuations and systematic risk, and the firm-specific productivity shock is the driving force of firm heterogeneity.

Finally, the equilibrium stochastic discount factor is given by:

$$
\begin{aligned}
\log M_{t, t+1} & =\log \beta+\gamma_{t}\left(\log X_{t}-\log X_{t+1}\right) \\
\gamma_{t} & =\gamma_{0}+\gamma_{1}\left(\log X_{t}-\log \bar{X}\right)
\end{aligned}
$$

where $M_{t, t+1}$ denotes the stochastic discount factor from time $t$ to $t+1$. The parameters $\left\{\beta, \gamma_{0}, \gamma_{1}\right\}$ are constants satisfying $1>\beta>0, \gamma_{0}>0$ and $\gamma_{1}<0$. According to equation (18), $\gamma_{t}$ is time-varying and decreases in the demeaned aggregate productivity shock $\log X_{t}-\log \bar{X}$ to capture the well documented countercyclical price of risk with $\gamma_{1}<0$. The precise economic mechanism driving the countercyclical price of risk can be, for example, timevarying risk aversion as in Campbell and Cochrane (1999).

\subsection{Calibration}

The model is solved at monthly frequency. In total 100 artificial samples are simulated from the model, each with 3,600 firms and 1,000 month. The initial condition for the simulations consists of skilled and unskilled stocks of all firms at their long-run average level and firmspecific productivity of all firms drawn from the unconditional distribution of $Z_{i t}$. The first 400 months are dropped to neutralize the impact of the initial condition. The remaining 600 months of simulated data are treated as from the model's stationary distribution. The sample size is largely comparable to the merged CRSP/Compustat dataset. Because all the 
quantity variables in the data are available only at the annual frequency, we aggregate the monthly quantity variables to the annual frequency and we calibrate the model to match selected annual moments as close as possible.

Table 1 reports the parameter values used to solve the baseline model. To isolate the effect of skilled labor adjustment costs on equilibrium risk premiums, we set the technology parameters for skilled and unskilled labor as symmetric as possible, except that their adjustment costs are different, with $c^{s}>c^{u}$ (we experiment with alternative values below). This leads to the shares of skilled labor and unskilled labor $\alpha^{s}$ and $1-\alpha^{s}$ both at 0.5 , and the quit rates for skilled and unskilled workers both at $3 \%$ per month, roughly consistent with the estimate in Davis, Faberman, and Haltiwanger (2006) and the estimate in Job Openings and Labor Turnover Survey (JOLTS). In addition, the wage rate of the skilled worker is higher to capture the obvious fundamental distinctive features of the two labor inputs.

\section{[Insert Table 1 Here]}

We set the returns to scale parameter $\theta=0.65 .^{7}$ The elasticity of substitution between skilled labor and unskilled labor $\phi$ is at 1.5 following Acemoglu (2002). As we report below, the time series average of the wage rate in high skilled industries is about $50 \%$ larger than the time series average wage rate in low skilled industries. Thus, we set the level wage rate parameters to be $\lambda^{s}=1.5$ and $\lambda^{u}=\frac{\lambda^{s}}{1.5}=1$. We set the sensitivity of the wage rate parameters to the productivity shocks $\eta^{s}$ and $\eta^{u}$ to be 0.75 , which implies the wage rate volatility is $1.3 \%$ per annum, close to the volatility of annual aggregate wages. ${ }^{8}$ The average level of the factor productivity is a scale parameter. We set $\bar{X}$ to be 1.5 to capture the fact that skilled labor is more productive than unskilled labor, and this difference should be close to the difference in their average wage rate, as implied by any general equilibrium

\footnotetext{
${ }^{7}$ More specifically, the returns to scale parameter $\theta$ is set to 0.65 to capture the total labor share in a more general production function where capital exists but is fixed at a constant, e.g., $Y_{t}=$ $K_{t}^{1-\theta}\left[\alpha^{s}\left(X_{t} N_{t}^{s}\right)^{\frac{\phi-1}{\phi}}+\left(1-\alpha^{s}\right)\left(N_{t}^{u}\right)^{\frac{\phi-1}{\phi}}\right]^{\frac{\phi \theta}{\phi-1}}$, where $K_{t}=1$.

${ }^{8}$ Because there is no separate data for the wages of skilled workers and unskilled workers, we match the volatility of aggregate wages.
} 
model (Recall that the factor productivity for unskilled labors is assumed to be constant and normalized to 1$)$.

We set the persistence of the aggregate productivity shock at $\rho_{x}=0.98^{1 / 3}$ and its conditional volatility at $\sigma_{x}=0.007 / \sqrt{3}$, which roughly corresponds to the quarterly estimates in King and Rebelo (1999). To calibrate the persistence parameter $\rho_{z}$ and the conditional volatility parameter $\sigma_{z}$ of the firm-specific productivity shock, we follow Zhang (2005) and restrict these two parameters using their implications on the degree of dispersion in the cross-sectional distribution of firms' stock return volatilities. Thus we set $\rho_{z}=0.97$, and $\sigma_{z}=0.20$, which implies an average annual volatility of individual stock returns of $38 \%$, approximately the value of $32 \%$ reported in Vuolteenaho (2001).

\subsection{Testable predictions}

To obtain a set of testable predictions on the link between risk premium, the degree of skilled labor, and the total hiring rate across industries, we compare the following three scenarios. In the first case, we set the skilled labor adjustment cost to be very low, in particular, we set these costs to be zero $\left(c^{s}=0\right)$. In the second specification we consider an intermediate adjustment costs in skilled labor $\left(c^{s}=5\right)$. In the third specification we consider high adjustment cost in skilled labor $\left(c^{s}=50\right)$. In all cases, the unskilled labor adjustment cost parameter is small, $c^{u}=1$. The first case corresponds to a low skilled labor industry, whereas the last case corresponds to an industry with highly skilled labor.

\section{[Insert Figure 1 Here]}

Figure 1 reports our main testable prediction from the model. The figure plots the hiring return spread implied by the solution of the model in these three alternative cases. The definition of the hiring return spread follows from Belo, Lin, and Bazdresch (2012), which is the average return difference between the bottom decile (firms with low hiring rates) and the top decile portfolios (firms with high hiring rates) sorted on firms' labor hiring rates. 
According to this figure, the hiring return spread is positive in all cases, a result consistent with the empirical results in Belo, Lin, and Bazdresch (2012).

The key analysis in our framework is to understand how the skilled labor adjustment cost parameter affects the magnitude of the hiring-expected return relation. According to Figure 1, the hiring return spread is strongly increasing in the size of skilled labor adjustment cost. The difference in hiring spread in the low skilled industry $\left(c^{s}=0\right)$ and high skilled industry $\left(c^{s}=50\right)$ is economically large, around $2 \%$. This shows that as the skilled labor adjustment cost parameter $c^{s}$ increases, the expected return-hiring relation becomes steeper. Given the importance of this central prediction in our analysis, we state it explicitly as a hypothesis.

H1: Hiring Frictions Hypothesis. Risk premium is decreasing in firms' hiring rates when $c^{s}, c^{u}>0$. This negative expected return-hiring relation is steeper for firms in industries in which labor adjustment costs are higher. If labor adjustment costs are higher for more skilled labor, then the negative expected return-hiring relation should be steeper in industries with a higher degree of skilled labor.

The economic intuition for the two results underlying this hypothesis is as follows. First, the negative expected return-hiring relationship is a standard result that follows from standard q-theory (see Belo, Lin, and Bazdresch, 2012). Optimal labor hiring by firms is high when the expected future marginal profitability of labor inputs is high, or when the discount rate (cost of capital), used to value future marginal profitability of labor is low, or both. Thus, the negative link between labor hiring and expected stock returns (risk) is negative, consistent with the evidence in previous studies.

Second, the negative expected return-hiring relation is steeper for firms in industries in which labor adjustment costs is higher is also intuitive. When the hiring of skilled workers is close to frictionless, $c^{s} \rightarrow 0$, hiring becomes infinitely elastic to changes in the discount rate (risk premium). With hiring frictions, $c^{s}>0$, hiring of skilled workers entails costs, and higher magnitude of hiring rate entails higher costs. As such, hiring is less elastic to the discount rate. The crucial observation for our empirical tests is that the magnitude 
of this elasticity decreases with $c^{s}$. The higher is $c^{s}$, the less elastically hiring responds to changes in the discount rate. That is, the higher is $c^{s}$, a given magnitude change in hiring rate corresponds to a higher magnitude change in the discount rate. This effect means that the negative expected return-hiring relation is steeper for firms with high labor adjustment costs, which we identify as firms in industries with higher degree of skilled labor, than for firms with low hiring adjustment costs. Our main empirical analysis is centered around this hiring friction hypothesis.

We can also use the model to make additional unconditional predictions regarding the degree of skilled labor and risk premium. Figure 2 shows the difference in the average returns between high skilled industry $\left(c^{s}=50\right)$ and low skilled industry $\left(c^{s}=5\right)$ for three categories of firms: small firms, medium firms, and large firms. We construct ten portfolios sorted on firms' ex dividend stock price and then calculate the return difference between high skilled and low skilled industries for each group of firms. Small firms are the bottom decile of the size portfolios, medium firms are the average of the fifth and sixth size portfolios, and large firms are the top decile. The figure shows that risk premium differential between high skilled and low skilled industry is much bigger in small firms (1.20) than in large firms $(-0.15)$.

[Insert Figure 2 Here]

H2: Labor Skill Return Spread and Firm Size Hypothesis. Firms in industries with high degree of skilled labor (higher $c^{s}$ ) have higher levels of expected returns, but this difference is only large across small firms.

The positive relationship between the size of adjustment costs and the firm's risk is well known in model's with physical capital (e.g., Jermann 1998; Zhang 2005). In production economies, the firm's risk is inversely related to its flexibility in using investment (here, hiring) to mitigate the effect of shocks on its dividend stream. The more flexible a firm is in this regard, the less risky it is. The size of the adjustment costs controls the firm's ability to smooth its dividends, and hence controls its flexibility. Thus, here, the higher the 
skilled labor adjustment costs a firm faces, the less flexible it is in adjusting its skilled labor force, and thus the more risky the firm is. Small firms are affected more by the increase in the adjustment cost parameter because the production function exhibits decreasing return to scale, but the adjustment cost is constant returns to scale. As such, small firms take on disproportionately higher adjustment costs which in turn make them more risky.

\section{Data}

In this section we describe the asset prices data, accounting data, and labor market variables used in our empirical tests.

\subsection{Asset prices and accounting data}

Monthly stock returns are from the Center for Research in Security Prices (CRSP), and accounting information is from the CRSP/Compustat Merged Annual Industrial Files. The sample is from July 1988 to June 2010 (the sample is constrained by the labor market data). As standard, we omit firms whose primary standard industry classification (SIC) is between 4900 and 4999 (regulated firms) or between 6000 and 6999 (financial firms). We require a firm to have a fiscal year-end in the last quarter of the year, to roughly align the accounting data across firms (results are nearly identical if we require a December fiscal-year-end). We include firms with common shares ( $\operatorname{shrcd}=10$ and 11) and firms traded on NYSE, AMEX, and NASDAQ (exchcd=1,2, and 3). We correct for the delisting bias following the approach in Shumway (1997). Finally, the data for the market factor (MKT) used in the tests of the unconditional capital asset pricing model (CAPM) is from Kenneth French's Web page.

We are interested in examining the relationship between hiring (and investment) with future stock returns across industries with different levels of labor skill. We construct the investment and hiring rate as in Belo, Lin and Bazdresch (2012) (see also Davis, Faberman, and Haltiwanger, 2006; and Bloom, 2009). The firm-level hiring rate is given by 
$\mathrm{HN}_{t}=\mathrm{H}_{t} /\left(0.5 \times\left(\mathrm{N}_{t-1}+\mathrm{N}_{t}\right)\right)$, in which the number of employees $\left(\mathrm{N}_{t}\right)$ is given by Compustat data item EMP, and net hiring $\left(\mathrm{H}_{t}\right)$ is given by the change in the number of employees in year $t$ from year $t-1\left(\mathrm{H}_{t}=\mathrm{N}_{t}-\mathrm{N}_{t-1}\right)$. By construction, this measure of labor hiring is symmetric around zero and bounded between $\pm 200 \%$. The firm-level investment rate is given by $\mathrm{IK}_{t}=\mathrm{I}_{t} /\left(0.5 \times\left(\mathrm{K}_{t-1}+\mathrm{K}_{t}\right)\right)$, in which the physical capital stock $\left(\mathrm{K}_{t}\right)$ is given by data item PPENT (net property plant and equipment), and physical capital investment $\left(\mathrm{I}_{t}\right)$ is given by Compustat data item CAPX (capital expenditures) minus SPPE (sales of property, plant, and equipment). Missing values of SPPE are set to zero.

We also keep track of the following accounting variables. Market equity (size) is price times shares outstanding at the end of December of $t$, from CRSP. Lev is book-leverage. ${ }^{9}$ The physical capital-to-market equity ratio (KM) is the ratio of the firm's physical capital stock and market equity. Firms' sales are given by data item SALE. Real sales growth ( $\Delta$ Sales) rate is thus measured by the ratio of the change in the sales from year $t$ to year $t-1$ to the sales in year $t-1$, deflated by the consumer price index. The firm's capital to labor ratio is given by the log of the ratio of the firms physical capital stock $\left(\mathrm{K}_{t}\right)$ deflated by the consumer price index, to the number of employees.

We exclude from the sample the firm-year observations with missing or negative capital stock data, missing number of employees and capital expenditures data, and missing preparation (Prep) data (our main labor skill variable as we describe in the next section). The final sample includes a total of 53,928 firm-year observations, which correspond to a total of 7, 827 firms.

\footnotetext{
${ }^{9}$ Following Liu, Whited, and Zhang (2009), book leverage is given by $\mathrm{Lev}=(\mathrm{DLTT}+\mathrm{DLC}) /(\mathrm{DLTT}+\mathrm{DLC}+\mathrm{ME})$ in which: DLTT is Long-Term Debt - Total, DLC is Debt in Current Liabilities - Total, and ME is market equity.
} 


\subsection{Measuring industry-level labor skills}

The key measure of industry level labor skills is given by the variable skill. In general terms, this measure is the fraction of high skilled workers in a given industry, in which skill is defined based on an index of the number of years required for a typical worker in the industry to perform the regular tasks associated with a job in a given industry. This index is a comprehensive because it combines information on the estimated number of years of formal education, on-the-job training, and past experience required to perform the regular tasks associated with a given job. This variable was first used in Donangelo (2012) as an intermediate step to construct a measure of labor mobility, which is not the focus of our analysis. $^{10}$

The skill variable is constructed based on the JobZones index from Occupational Information Network $\left(\mathrm{O}^{*} \mathrm{Net}\right)$, available at http://www.onetonline.org/find/zone. For each occupation $j$ in year $t$, the JobZones index is an occupation-specific index of formal preparation $\left(\mathrm{FP}_{j, t}\right)$ which takes values from $\mathrm{FP}_{j, t}=1$ (low preparation) to $\mathrm{FP}_{j, t}=5$ (high preparation). Because this index is available at the occupation, not industry, level, we compute an industry-level index by computing the average (across all occupations) of the workers in the industry that work on an occupation that belong to JobZones index $\mathrm{FP}=4,5$ (i.e. occupations with index of formal preparation of 4 or 5). ${ }^{11}$ We focus on this measure due to its simplicity and obvious interpretation. ${ }^{12}$ The data to compute the number of workers by occupation in each industry is from the Bureau of Labor Statistics (BLS), Occupational Employment Statistics (OES) program. The data is available since 1988, which imposes a constraint on the beginning of our sample. We classify an industry using three-digit Standard Industrial Classification (SIC) codes until 2001, and four-digit North American

\footnotetext{
${ }^{10}$ We thank Andres Donangelo for sharing his data with us.

${ }^{11}$ See Donangelo, 2012, for a similar approach.

${ }^{12}$ We note that the results that reported here are robust to the use of other industry level measures of labor skills. For example, when we use the industry-level average across all the JobZones index, we obtain similar results to those reported here. Also, when we use a measure of the average level of education of the workers in a given industry, we obtain again similar results (results available upon request).
} 
Industry Classification System (NAICS) codes after 2001.

To help understand this variable, Table 2 reports the top 10 (Panel A) and bottom 10 (Panel B) industries sorted on average labor skill in 2010. In this year, there are a total of 187 NAICS industries. Computer related industries are classified as high skilled labor industries. We also note that health care related industries rank very high as well, although they are not in the top 10. Limited-service eating places, and full-service restaurants industries are low skilled labor industries. The ranking conforms with our priors regarding the degree of required labor skills across these industries.

\section{[Insert Table 2 Here]}

\section{Empirical results}

In this section we test the key prediction from the theoretical analysis: the negative expected return-hiring relation is steeper for firms with high labor adjustment costs (H1), which we identify as firms in industries with higher levels of skilled labor. We follow two complementary empirical methodologies to examine the previous relationship. In the first approach, we construct portfolios sorted on the variable of interest, and in the second approach we run standard firm-level regressions that control for firm and year fixed effects (for example, see Fama and French (2008) for a discussion on the advantages and disadvantages of each approach). The two approaches allow us to cross-check the results and establish the robustness of the findings. We also examine the unconditional link between skilled labor and risk premia across industries, to investigate the labor skill return premium and firm size hypothesis $(\mathrm{H} 2)$.

\subsection{Labor skill and stock returns}

Before we examine the link between labor hiring and stock returns across industries with different levels of skilled labor, we first investigate the unconditional link between labor skill 
and stock returns in the cross section, that is, we study the labor skill return spread and firm size hypothesis (H2). We construct ten (and two) one-way-sorted labor skills portfolios as follows. Following Fama and French (1993), at the end of June of year $t$, we first sort the universe of common stocks into ten (or two) portfolios based on the deciles (median) of the cross-sectional distribution of the firm-level labor skill variable (Prep) at the end of year $t-1$. Once the portfolios are formed, their returns are tracked from July of year $t$ to June of year $t+1$. The procedure is repeated in June of year $t+1$.

In this section, we report both equal-weighted and value-weighted portfolio returns to investigate if the link between labor skill and stock returns varies with firm size as predicted by the theoretical model. In the subsequent analysis however, we will focus most of our discussion on the results for value-weighted portfolios because of the low transaction costs associated with value-weighted investment strategies. Value-weighted portfolios are not necessarily well diversified portfolios, however, because of the heavy tails of the size distribution in the US stock market. As discussed in Fama and French (2008), and Malevergne, Santa-Clara, and Sornette (2011), the characteristics of value-weighted portfolios are dominated by a small number of very large (mega cap) firms. ${ }^{13}$ Thus, to provide a balanced analysis of the link between hiring and stock returns in the overall economy, we impose a cap of $5 \%$ on the maximum weight of each firm in the portfolio at the time of portfolio formation before computing the value-weighted portfolio returns. This choice guarantees that the minimum effective number of firms in each portfolio is twenty.

\section{[Insert Table 3 Here]}

The top left panel in Table 3 reports the average excess stock returns $\left(R^{\mathrm{e}}\right)$ of the ten oneway-sorted labor skill portfolios (to save space, we report the characteristics for portfolios 1-Low, 5-Mid, and 10-High). The equal weighted average excess returns of the labor skill portfolios are strongly increasing in the level of labor skill. The average excess returns of the firms in the high labor skilled industries is about $9.8 \%$ per annum higher than in industries

\footnotetext{
${ }^{13}$ See also, Belo, Lin, and Bazdresch (2012).
} 
with low skilled labor, and this difference is more than 1.7 standard errors from zero (given the small sample size and the volatility of stock returns, obtaining strong statistical significance is naturally challenging). We refer to this difference as the labor skill return spread. However, we don't see much difference in the value-weighted average excess returns of the labor skill portfolios. Here, the average excess returns of the firms in the high labor skilled industries is about $2.3 \%$ per annum higher than in industries with low skilled labor, but this difference is only 0.4 standard errors from zero.

Table 3 also reports the time series average of median portfolio-level characteristics of the labor skill portfolios. Interestingly, this table shows that firms in more skilled industries tend to have much smaller leverage ratios than firms in low skilled industries. This fact may explain why we don't observe a high difference in the equity (levered) returns when we use value-weighted portfolios - if delevered, the differences should increase substantially. In addition, firms in more skilled industries tend to have higher sales growth, and are more labor intensive (measured by lower capital to labor ratios). Also, firms in more skilled industries offer higher wages, consistent with the large labor economics and macroeconomic literatures on the skill premium. Finally, firms in high skilled labor industries tend to be slightly smaller (size), and have lower book-to-market equity ratios (BM), a characteristic of a value firm.

The analysis of the characteristics of the two labor skill portfolios reported in the panel $\mathrm{B}$ of Table 3 is similar to the analysis of the characteristics of the ten labor skill portfolios, so we omit the detailed analysis here. In what follows, and for tractability, we investigate the link between hiring (and investment) and stock returns across these two labor skill portfolios.

Taken together, the analysis in this section documents a large and positive labor skill return spread in equal-weighted portfolio returns (9.8\% per annum) but not across valueweighted portfolios. Thus, the results here are overall consistent with the models' predictions, in particular, the labor skill return spread and firm size hypothesis (H2). 


\subsection{Labor skill, hiring, and stock returns}

We now test the main hiring friction hypothesis (H1) from the theoretical analysis, that is, the negative expected return-hiring relation is steeper for firms in industries with highly skilled labor (high labor adjustment costs). To that end, we construct five one-way-sorted hiring portfolios and investigate the characteristics of the portfolio's post-formation average excess stock returns (in excess of the risk-free rate). We form the five hiring portfolios separately across low and high skilled industries (cutoff at the median of the cross sectional distribution of labor skill). We then construct the hiring portfolios as follows. At the end of June of year $t$, we first sort the universe of common stocks into five portfolios based on the quintile of the cross-sectional distribution of the firm-level hiring rate at the end of year $t-1$ separately across low and high skilled labor industries. Once the portfolios are formed, their value-weighted returns are tracked from July of year $t$ to June of year $t+1$. The procedure is repeated in June of year $t+1$. As with the labor skill portfolios, when computing value-weighted returns, we impose a cap of $5 \%$ on the maximum weight of each firm in the portfolio at the time of portfolio formation.

\section{[Insert Table 4 Here]}

The top left panel in Table 4 reports the average excess stock returns $\left(R^{\mathrm{e}}\right)$ of the five oneway-sorted hiring portfolios across all firms in the economy. Consistent with the findings in Belo, Lin, and Bazdresch (2012), the average excess returns of the portfolios are decreasing in the hiring rate, and the sorting procedure generates a large spread in returns. Firms with low hiring rates outperform firms with high hiring rates (L-H) by 7.2 per annum, and this value is more than 2.2 standard errors from zero- the hiring return spread.

The middle and bottom panels in Table 4 reports our new empirical finding. The hiring return spread is substantially smaller across firms that belong to industries with low skilled labor, than across firms that belong to industries with high skilled labor. In particular, the hiring return spread is $3.7 \%$ per annum in low skill labor industries, and this value is only 
1.4 standard errors from zero. In high skill labor industries, the hiring return spread is $7 \%$ per annum, and this value is more than 1.8 standard errors from zero. So, the hiring return spread is two times larger in high skill labor industries than in low skill labor industries. The negative expected return-hiring relation is thus indeed steeper for firms in industries with highly skilled labor, consistent with the hiring friction hypothesis.

\subsection{Labor skill, hiring, investment, and stock returns}

The simple model we consider in the theoretical section ignores physical capital. In the real world, however, firms do have access to both labor and capital inputs. In this section, we investigate if the link between hiring and stock returns across industries with different levels of labor skills varies in a way that is consistent with the theoretical model even after controlling for the firms' investment rate. Controlling for investment is important given the fact that previous studies document a strong negative relationship between the firm's physical capital investment rate and expected stock returns in the cross section (see reference in the introduction section). Naturally, hiring and investment are positively correlated because they are complementary inputs in most production functions (in our sample, this correlation is $30 \%$ at the firm level, not tabulated). In this section, we thus extend the previous analysis to investigate the joint link between hiring, investment, and stock returns across industries with different levels of labor skill using two-way-sorted portfolios. In addition, as a complementary approach, we also run firm-level regressions to control for firm and time fixed effects.

\subsubsection{Double-sorted portfolios}

We form nine portfolios two-way-sorted on investment and hiring as follows. We first allocate firms to low skilled and high skilled labor industries based on the median value of the crosssectional distribution of the industry labor skill variable. At the end of each June of year $t$, we sort the each group of firms into three portfolios based on the firm's investment rate. Then, each one of these three investment portfolios is equally sorted into three portfolios 
based on the firm's hiring rate. The investment rate and hiring rate breakpoints for year $t$ are the $33^{\text {th }}$ and $66^{\text {th }}$ percentiles of the cross-sectional distribution of the corresponding sorting variable in low or high skilled industry at the end of year $t-1$. Once the portfolios are formed, their value-weighted returns are tracked from July of year $t$ to June of year $t+1$. The procedure is repeated in June of year $t+1$. This sequential sorting guarantees an equal number of firms in each portfolio. As with the previous portfolios, we impose a cap of $5 \%$ on the maximum weight of each firm in the portfolio at the time of portfolio formation.

\section{[Insert Table 5 Here]}

The top and bottom left panels in Table 5 shows that the double-sorting procedure generates an reasonable spread in average excess returns both across the hiring (row L-H) and investment (column L-H) dimensions, but the spreads are considerably larger in high skill labor industries. In both cases, the average excess returns of the portfolios tend to decrease in both the hiring and investment rates. Thus, the hiring rate is correlated with future stock returns even after accounting for the effect of the investment rate (and vice versa for the investment rate).

The column labeled Avg Spread in Table 5 summarizes the key results obtained from the analysis of the nine double-sorted portfolios. Instead of examining the properties of each one of the nine portfolios and of the six low minus high portfolios individually, we create two return spread portfolios, which we refer to as the hiring (HN) and investment (IK) return spread portfolios. These portfolios are constructed as follows. This new hiring return spread is the average of the three low-hiring minus high-hiring portfolios across the three investment portfolios. Similarly, the investment return spread is the average of the three low-investment minus high-investment portfolios across the three hiring portfolios.

The results for the average spread portfolios revel that hiring return spread is indeed substantially larger among high skill labor industries than in low skill labor industries. Controlling for the investment rate, the hiring return spread is only $1.6 \%$ per annum in industries with low skilled labor. This value is only 1 standard error from zero. In contrast, 
controlling for the investment rate, the hiring return spread is $4.1 \%$ per annum and this value os more than 2 standard errors from zero. Thus consistent with the theoretical analysis, the negative expected return-hiring relation is steeper for firms in industries with highly skilled labor, even after controlling for the firm's investment rate.

\subsubsection{Firm-level regressions}

We now use a different approach to investigate the strength of the negative expected returnhiring relation among industries with different levels of labor skills. We run standard firmlevel pooled OLS regressions to predict stock returns using the lagged firm-level hiring and physical capital investment rates as return predictors. As discussed in Fama and French (2008), it is difficult to draw inferences about which sorting variables has unique information about average returns using a portfolio approach. In addition, the portfolio procedure requires the specification of breakpoints and order of the sorting procedure, which in turn may influence the overall analysis. Thus, these alternative firm level regressions allow us to cross-check the results and establish the robustness of the findings.

To control for firm and year fixed-effects, we run pooled OLS regressions:

$$
R_{i t+1}^{e}=a_{i}+c_{t+1}+\beta_{\mathrm{hn}} \mathrm{HN}_{i t}+\beta_{\mathrm{ik}} \mathrm{IK}_{i t}+e_{i t+1}
$$

in which $R_{i t+1}^{e}$ in the firm i excess stock return in year $\mathrm{t}+1$ (annual), $\mathrm{a}_{i}$ is firm i fixedeffect, $\mathrm{c}_{t+1}$ is a year fixed-effect, and $\mathrm{HN}_{i t}$ and $\mathrm{IK}_{i t}$ are the lagged values of firm $\mathrm{i}$ hiring and investment rates, respectively. Standard errors are clustered by firm and year. We report the results for all possible combinations of the fixed-effects. In addition, we report results separately across industries with low and high skill labor. The explanatory variables are standardized to have zero mean and unit standard deviation, so the slope coefficient can be interpreted as the effect on firms' stock return (in percentage, per annum) of a unit standard deviation increase of the explanatory variable. 
[Insert Table 6 Here]

The results reported in Table 6 confirms the results from the portfolio level approach. The hiring and investment rates remain joint strong predictors, with negative slope, even after accounting for firm and year fixed effects. More important, the comparison of the results from specifications 3 versus 6 when both firm and year fixed-effects are included, shows that the negative slope of the hiring rate is higher in industries with high levels of labor skill. In particular, among low skill labor industries, a one standard deviation increase in the firm hiring rate is associated with a $2.3 \%$ decrease in the firm's annual stock return, controlling for the firm's investment rate. In high skill labor industries the effect is much larger. Here, a one standard deviation increase in the firm hiring rate is associated with a $5.4 \%$ decrease in the firm's annual stock return, controlling for the firm's investment rate. That is, the hiring rate negative slope coefficient in high labor skill industries is more than twice the (absolute) value of the hiring rate negative slope coefficient in low labor skill industries.

\subsection{Asset pricing tests}

In this section, we investigate the extent to which the hiring return spread across different labor skill industries can be explained by exposure to standard risk factors, as captured by the unconditional capital asset pricing model (CAPM). To test the CAPM, we run monthly time-series regressions of the excess returns of each portfolio on a constant and the excess returns of the market portfolio (market). The intercepts from this regression are the pricing errors.

The results reported in the top panel in Table 4 show that the CAPM cannot explain the pattern of the returns of these portfolios. The CAPM implied pricing errors $(\alpha)$ are large. The pricing error of the low minus high hiring portfolio is economically large, $8.5 \%$ per annum, which is more than 3 standard errors from zero, and is even larger than the hiring return spread itself $(7.2 \%)$.

More interestingly, the results show that the failure of the unconditional CAPM is more 
pronounced in high skilled labor industries. In low skilled labor industries, the pricing error of the low minus high hiring portfolio is $4.7 \%$ per annum, which is 1.7 standard errors from zero. In high skilled labor industries, the pricing error of the low minus high hiring portfolio is $8.7 \%$ per annum, which is 2.3 standard errors from zero. That is, the CAPM implied pricing errors of the low minus high hiring portfolio are two times larger in high skilled industries than in low skilled industries. That analysis of the CAPM results across the twoway sorted on hiring and investment portfolios across industries with different labor skills is qualitatively similar to the analysis of the one-way sorted on hiring portfolios, so we omit the analysis here.

The model we propose in the theoretical section is silent on why the unconditional CAPM fails in explaining the average returns of these portfolios. Addressing this issue requires adding more sources of aggregate risk, that is, change the SDF in the model (see Belo, Lin and Bazdresch, 2012; or Kogan and Papanikolaou, 2012), so that the one factor CAPM fails. The properties of the SDF however, is not the focus of the analysis in this paper, which concentrates mostly on the production side of the economy with a fairly standard SDF (Zhang, 2005).

In fact, the failure of the CAPM in our empirical analysis is consistent with the results in Belo, Lin, and Bazdresch (2012), who show that the unconditional CAPM fails in a model with two aggregate sources of risk and a homogenous labor input. The sources of aggregate risk are different, however. In Belo, Lin and Bazdresch (2012), high hiring firms are more exposed to an aggregate growth opportunity shocks which carry a negative price of risk in equilibrium. The CAPM then fails because the overall stock market return is driven by aggregate productivity shocks that are uncorrelated with the aggregate growth opportunity shocks. As a result, the CAPM is unable to capture the differential exposure of the firms in the hiring portfolios to the growth opportunity shocks, the driver of the hiring return spread. We believe the same mechanism should apply to the model with labor heterogeneity considered here if we incorporate the growth opportunity shock into the model. 
Because growth opportunity shocks affect labor adjustment costs as a proportional shift of the adjustment cost schedule, these shocks are more important for firms with higher skilled labor with higher labor adjustment costs. In turn, the previous analysis thus suggests that the CAPM should fail more in high labor skilled/high labor adjustment cost industries as we report here.

\section{Conclusion}

We show novel empirical linkages between the stock market and the labor market. We report three major findings. First, we show that the negative expected return-hiring relation identified in previous studies is steeper in industries in which the overall level of labor skill is higher. Theoretically, we combine a standard model of labor heterogeneity with a standard q-theory model to show that this result supports the hypothesis that the adjustment costs of labor are higher for more skilled workers, a hypothesis that is also consistent with labor adjustment cost estimates surveyed in Hamermesh (1993), and the results in Shapiro (1984). Second, the steeper negative expected return-hiring relation in industries with higher labor skills holds even after controlling for the effect of investment and stock returns. Finally, we document a positive link between the industry average level of labor skill and average returns, which we refer as the labor skill return spread. Firms in industries with higher labor skills have higher average returns than firms in industries with lower labor skills. This difference however, is only large across equal-weighted portfolios, not across value-weighted portfolios, which suggest that this labor skill return spread is only large among small firms, a finding that is consistent with the theoretical model proposed here. According to this result, firms with higher labor skills tend to be more risky because skilled labor is more costly to adjust, which in turn affects the firm's sensitivity to aggregate shocks in the economy.

Taken together, our results show that heterogeneity in the labor force across firms affects asset prices in financial markets in important ways. Our analysis has broader implications 
for both the asset pricing and labor economics literatures. Our findings suggest that labor market frictions can have a significant impact on asset prices, and that this effect varies with the characteristics of the labor force. Thus, financial market variables, which are typically ignored in the labor economics literature, can be a useful source of information about the importance of labor market frictions. Naturally, skilled labor varies in dimensions that go beyond simple differences in labor adjustment costs. For example, the skills of the labor force ultimately affect how firms' respond to aggregate shocks. Our results thus highlight the role of one specific difference: difference in labor adjustment costs between skilled and unskilled workers goes in the right direction for explaining the empirical links that we document here. Examining the impact of other labor related differences on asset prices is an interesting topic for future research.

\section{References}

[1] Acemoglu, Daron, 2001, Good jobs versus bad jobs, Journal of Labor Economics, 19(1), $1-21$

[2] Acemoglu, Daron, 2002, Technical change, inequality, and the labor market, Journal of Economic Literature, 40, 7 - 72

[3] Acemoglu, Daron., and David Autor, 2011, Skills, tasks and technologies: Implications for employment and earnings, Handbook of Labor Economics, 4(B), 1043 - 1171

[4] Asness, Clifford, R. Burt Porter, and Ross Stevens, 2000, Predicting stock returns using industry-relative firm characteristics, Working paper, Iowa State University

[5] Belo, Frederico, Xiaoji Lin, and Santiago Bazdresch, 2012, Labor hiring, investment, and stock return predictability in the cross section, working paper. 
[6] Bloom, Nicholas, 2009, The impact of uncertainty shocks, Econometrica, 77(3), $623-685$

[7] Bond, Stephen, and John Van Reenen, 2007, Microeconometric models of investment and employment, Handbook of econometrics, 6, 4417 - 4500

[8] Boyd, John H., Jian Hu, and Ravi Jagannathan, 2005, The stock market's reaction to unemployment news: Why bad news is usually good for stocks, Journal of Finance, $60(2), 649-672$

[9] Caballero, Ricardo. 2007, Specificity and the Macroeconomics of Restructuring. MIT Press

[10] Campbell, John Y., 1996, Understanding risk and return, Journal of Political Economy, $104,298-345$

[11] Cappelli, Peter, and Steffanie L. Wilk, 1997, Understanding selection processes: organization determinants and performance outcomes, Mimeo, The Wharton School

[12] Cochrane, John, 1991, Production-based asset pricing and the link between stock returns and economic fluctuations, The Journal of Finance 461, 209 - 237

[13] Danthine, Jean-Pierre, and John B. Donaldson, 2002, Labour relations and asset returns, Review of Economic Studies, 69(1), 41 - 64

[14] Davis, Steven, R. Jason Faberman, and John Haltiwanger, 2006, The flow approach to labor markets: New data sources and micro-macro links, Journal of Economic Perspectives, 20(3), $3-26$

[15] Diamond, Peter A, 1982, Aggregate demand management in search equilibrium, Journal of Political Economy, 90(5), 881 - 894

[16] Donangelo, Andres, 2012, Labor mobility: implications for asset pricing, working paper, University of Texas at Austin 
[17] Eisfeldt, Andrea and Dimitris Papanikolaou, 2012, Organizational capital and the cross-section of expected returns, Journal of Finance, forthcoming

[18] Fama, Eugene F., and Kenneth R. French, 1993, Common risk factors in the returns on stocks and bonds, Journal of Financial Economics 33, 3- 56

[19] Fama, Eugene F., and Kenneth R. French, 2008, Dissecting anomalies, Journal of Finance, 63(4), $1653-1678$

[20] Fama, Eugene F. and G. William Schwert, 1977, Human capital and capital market equilibrium, Journal of Financial Economics, 4(1), 95-125

[21] Hamermesh, Daniel S, 1993, Labor demand, $1^{\text {st }}$ ed, Princeton University Press

[22] Hamermesh, Daniel S and Gerard Pfann, 1996, Adjustment costs in factor demand, Journal of Economic Literature, XXXIV, 1264-1292

[23] Hayashi, Fumio, 1982, Tobin's marginal and average q: A neoclassical interpretation, Econometrica 50 (1), 213-224

[24] Jagannathan, Ravi and Zenyu Wang, 1996, The Conditional CAPM and the crosssection of expected returns, The Journal of Finance, 51, 3-53

[25] Jermann, Urban J, 1998, Asset pricing in production economies, Journal of Monetary Economics, 41(2), $257-275$

[26] Katz, Lawrence F. and Kevin M. Murphy, 1992, Changes in relative wages, 1963-1987: Supply and demand factors, The Quarterly Journal of Economics, 107(1), 35 - 78

[27] Kydland, Finn E., 1984, Labor-force heterogeneity and the business cycle, CarnegieRochester Conference Series on Public Policy, 21, 173 - 208 
[28] King, R. G, Rebelo, S. T., 1999. Resuscitating real business cycles. In: Taylor, J., Woodford, M. (Eds.), Handbook of Macroeconomics. North Holland, Amsterdam, pp. $927-1007$.

[29] Li, Dongmei and Lu Zhang, 2010, Does q-theory with investment frictions explain anomalies in the cross-section of returns?, Journal of Financial Economics, 98(2), $297-314$

[30] Liu, Laura X. L., Toni M. Whited, and Lu Zhang, 2009, Investment-based expected stock returns, Journal of Political Economy, 117(6), 1105 - 1139

[31] Lucas, Robert J., 1967, Optimal investment policy and the flexible accelerator, International Economic Review, 8, 78-85

[32] Lustig, Hanno, and Stijn Van Nieuwerburgh, 2008, The returns on human capital: Good news on wall street is bad news on main street, Review of Financial Studies, $21(5), 2097-2137$

[33] Lustig, Hanno, Chad Syverson, and Stijn Van Nieuwerburgh, 2011, Technological Change and the Growing Inequality in Managerial Compensation, Journal of Financial Economics, 99(3), 601-627

[34] Malevergne, Yannick, Pedro Santa-Clara, and Didier Sornette (2011), Professor Zipf goes to Wall Street, Working Paper

[35] Mayers, David, 1972, Non-marketable assets and capital market equilibrium under uncertainty, in Jensen, M. Studies in the Theory of Capital Markets, Praeger, New York, 223-248

[36] Merz, Monika, and Eran Yashiv, 2007, Labor and the market value of the firm, American Economic Review, 97 (4), 1419-1431 
[37] Mortensen, Dale T, 1982, Property rights and efficiency in mating, racing, and related games, American Economic Review, 72(5) 968 - 979

[38] Nadiri, M. Ishaq, and Sherwin Rosen, 1969, Interrelated factor demand functions, American Economic Review, 59, 457-471

[39] Ochoa, Marcelo, 2012, Labor heterogeneity, volatility, and expected equity returns, Working Paper

[40] Pissarides, Christopher A., 1985, Short-run equilibrium dynamics of unemployment, vacancies, and real wages, American Economic Review, 75(4), 676 - 690

[41] Rouwenhorst, K. Geert, 1995, Asset pricing implications of equilibrium business cycle models, In Frontiers of business cycle research, Ed T.F. Cooley(ed), Princeton University Press, $294-330$

[42] Santos, Tano and Pietro Veronesi, 2006, Labor Income and Predictability of Stock Returns, Review of Financial Studies, 19, 1-44

[43] Shapiro, Matthew D, 1986, The dynamic demand for capital and labor, Quarterly Journal of Economics, 101(3), 513 - 542

[44] Shumway, Tyler, 1997, The delisting bias in CRSP data, 1997, Journal of Finance, 52, $327-340$

[45] Tauchen, George, and Robert Hussey, 1991, Quadrature-based methods for obtaining approximate solutions to nonlinear asset pricing models, Econometrica, 59(2), 371-396

[46] Uhlig, Harald, 2007, Explaining asset prices with external habits and wage rigidities in a DSGE model, American Economic Review, 97, 239-243

[47] Yashiv, Eran, 2000, Hiring as investment behavior, Review of Economic Dynamics, 3, $486-522$ 
[48] Zhang, Lu, 2005, The value premium, The Journal of Finance, 60(1), 67 - 103 


\section{A Proof of Proposition 1}

We first show $P_{t}=Q_{t}^{s} N_{t+1}^{s}+Q_{t}^{u} N_{t+1}^{u}$. The production function is constant return to scale in $\left(N_{t}^{s}, N_{t}^{u}\right)$ with $\theta=1$, this leads to

$$
Y_{t}=\frac{\partial Y_{t}}{\partial N_{t}^{s}} N_{t}^{s}+\frac{\partial Y_{t}}{\partial N_{t}^{u}} N_{t}^{u}
$$

The first order conditions w.r.t. $H_{t}^{s}, H_{t}^{u}, N_{t+1}^{s}$, and $N_{t+1}^{u}$ are

$$
\begin{aligned}
Q_{t}^{s} & =c^{s} \frac{H_{t}^{s}}{N_{t}^{s}} \\
Q_{t}^{u} & =c^{u} \frac{H_{t}^{u}}{N_{t}^{u}} \\
Q_{t}^{s} & =\mathbb{E}_{t} M_{t, t+1}\left[\frac{\partial Y_{t+1}}{\partial N_{t+1}^{s}}-W_{t+1}^{s}+\frac{c^{s}}{2}\left(\frac{H_{t+1}^{s}}{N_{t+1}^{s}}\right)^{2}+\left(1-\delta^{s}\right) Q_{t+1}^{s}\right], \\
Q_{t}^{u} & =\mathbb{E}_{t} M_{t, t+1}\left[\frac{\partial Y_{t+1}}{\partial N_{t+1}^{u}}-W_{t+1}^{u}+\frac{c^{u}}{2}\left(\frac{H_{t+1}^{u}}{N_{t+1}^{u}}\right)^{2}+\left(1-\delta^{u}\right) c^{u} \frac{H_{t+1}^{u}}{N_{t+1}^{u}}\right] .
\end{aligned}
$$

Transversality conditions for $N_{t+j+1}^{s}$ and $N_{t+j+1}^{u}$ are

$$
\begin{aligned}
& \lim _{j \rightarrow \infty} \mathbb{E}_{t} M_{t, t+j} Q_{t+j}^{s} N_{t+j+1}^{s}=0, \\
& \lim _{j \rightarrow \infty} \mathbb{E}_{t} M_{t, t+j} Q_{t+j}^{u} N_{t+j+1}^{u}=0 .
\end{aligned}
$$

Rewrite the firm's cum dividend market value as the sum of ex. dividend stock price and dividend

$$
V\left(x_{t}\right)=P_{t}+D_{t}
$$

With equation (5), we have

$$
V\left(x_{t}\right)=P_{t}+Y_{t}-W_{t}^{s} N_{t}^{s}-W_{t}^{u} N_{t}^{u}-\frac{c^{s}}{2}\left(\frac{H_{t}^{s}}{N_{t}^{s}}\right)^{2} N_{t}^{s}-\frac{c^{u}}{2}\left(\frac{H_{t}^{u}}{N_{t}^{u}}\right)^{2} N_{t}^{u} .
$$

Expand the firm's maximization problem as

$$
\begin{aligned}
V\left(x_{t}\right)= & \mathbb{E}_{t} \sum_{j=0}^{\infty} M_{t, t+j}\left\{\left[Y_{t+j}-W_{t+j}^{s} N_{t+j}^{s}-W_{t+j}^{u} N_{t+j}^{u}-\frac{c^{s}}{2}\left(\frac{H_{t+j}^{s}}{N_{t+j}^{s}}\right)^{2} N_{t+j}^{s}-\frac{c^{u}}{2}\left(\frac{H_{t+j}^{u}}{N_{t+j}^{u}}\right)^{2} N_{t+j}^{u}\right]\right. \\
& -Q_{t+j}^{s}\left[K_{t+j+1}^{s}-(1-\delta) K_{t+j}^{s}-H_{t+j}^{s}\right] \\
& \left.-Q_{t+j}^{u}\left[K_{t+j+1}^{u}-(1-\theta) K_{t+j}^{u}-H_{t+j}^{u}\right]\right\} .
\end{aligned}
$$

Recursively substituting equations (2), (3), (A1), and (A2)-(3) and using the fact that the adjustment costs are homogeneous degree of one in $(H, N)$ and the transversality conditions, 
we get the following after canceling out the intermediate terms:

$$
P_{t}=Q_{t}^{s} N_{t+1}^{s}+Q_{t}^{u} N_{t+1}^{u}
$$

Now we prove $R_{t+1}^{e}=\frac{Q_{t}^{s} N_{t+1}^{s}}{P_{t}} R_{t+1}^{s}+\frac{Q_{t}^{u} N_{t+1}^{u}}{P_{t}} R_{t+1}^{u}$. With equations (5) and (6), we have

$$
R_{t+1}^{e}=\frac{P_{t+1}+Y_{t+1}-W_{t+1}^{s} N_{t+1}^{s}-W_{t+1}^{u} N_{t+1}^{u}-\frac{c^{s}}{2}\left(\frac{H_{t+1}^{s}}{N_{t+1}^{s}}\right)^{2} N_{t+1}^{s}-\frac{c^{s}}{2}\left(\frac{H_{t+1}^{u}}{N_{t+1}^{u}}\right)^{2} N_{t+1}^{u}}{P_{t}}
$$

Using what we have proved in equation (A10) and change the date $t$ to $t+1$, we get

$R_{t+1}^{e}=\frac{Q_{t+1}^{s} N_{t+2}^{s}+Q_{t+1}^{u} N_{t+2}^{u}+Y_{t+1}-W_{t+1}^{s} N_{t+1}^{s}-W_{t+1}^{u} N_{t+1}^{u}-\frac{c^{s}}{2}\left(\frac{H_{t+1}^{s}}{N_{t+1}^{s}}\right)^{2} N_{t+1}^{s}-\frac{c^{u}}{2}\left(\frac{H_{t+1}^{u}}{N_{t+1}^{u}}\right)^{2} N_{t+1}^{u}}{P_{t}}$

Plugging equations (11), (12), and (A1), we get

$$
\begin{aligned}
R_{t+1}^{e} & =\frac{N_{t+1}^{s}\left[\frac{\partial Y_{t+1}}{\partial N_{t+1}^{s}}-W_{t+1}^{s}-\frac{c^{s}}{2}\left(\frac{H_{t+1}^{s}}{N_{t+1}^{s}}\right)^{2}+\left(1-\delta^{s}\right) Q_{t+1}^{s}\right]}{P_{t}} \\
+ & \frac{N_{t+1}^{u}\left[\frac{\partial Y_{t+1}}{\partial N_{t+1}^{u}}-W_{t+1}^{u}-\frac{c^{u}}{2}\left(\frac{H_{t+1}^{u}}{N_{t+1}^{u}}\right)^{2}+\left(1-\delta^{u}\right) Q_{t+1}^{u}\right]}{P_{t}} \\
= & \frac{Q_{t}^{s} N_{t+1}^{s}}{P_{t}} R_{t+1}^{s}+\frac{Q_{t}^{u} N_{t+1}^{u}}{P_{t}} R_{t+1}^{u}
\end{aligned}
$$

Q.E.D.

\section{Numerical Algorithm}

To solve the model numerically, we use the value function iteration procedure to solve the firm's maximization problem. The value function and the optimal decision rule are solved on a grid in a discrete state space. We specify a grid of 30 points for skilled and unskilled labor, respectively, with upper bounds $\bar{n}^{s}$ and $\bar{n}^{u}$ that are large enough to be nonbinding. The grids for skilled and unskilled labor stocks are constructed recursively, following McGrattan (1999), that is, $n_{i}=n_{i-1}+c_{n 1} \exp \left(c_{n 2}(i-2)\right)$, where $i=1, \ldots, 30$ is the index of grids points and $c_{n 1}$ and $c_{n 2}$ are two constants chosen to provide the desired number of grid points and two upper bounds $\bar{n}^{s}$ and $\bar{n}^{u}$, given two pre-specified lower bounds $\underline{\mathrm{n}}^{s}$ and $\underline{\mathrm{n}}^{u}$. The advantage of this recursive construction is that more grid points are assigned around $\bar{n}^{s}$ and $\bar{n}^{u}$, where the value function has most of its curvature.

The state variables $\log X$ and $\log Z_{i}$ have continuous support in the theoretical model, but they have to be transformed into discrete state space for the numerical implementation. The popular method of Tauchen and Hussey (1991) does not work well when the persistence level is above 0.9. Because both of the aggregate productivity processes for skilled and unskilled labor are highly persistent, we use the method described in Rouwenhorst (1995) 
for a quadrature of the Gaussian shocks. We use 5 grid points for both of $\log X$ and $\log Z_{i}$ processes. In all cases the results are robust to finer grids as well. Once the discrete state space is available, the conditional expectation can be carried out simply as a matrix multiplication. Cubic spline interpolation is used extensively to obtain optimal investment and hiring which do not lie directly on the grid points. Finally, we use a simple discrete, global search routine in maximizing the firm's problem. 
Table 1: : Benchmark Calibration

This table reports the benchmark parameters. The model is solved at an monthly frequency.

\begin{tabular}{lrl}
\hline \hline Parameter & Value & Description \\
\hline Firm's technology & \\
$\alpha^{s}$ & 0.5 & Share of skilled labor in the production function \\
$\delta^{s}$ & 0.03 & Skilled labor separation rate \\
$\delta^{u}$ & 0.03 & Unskilled labor separation rate \\
$\theta$ & 0.65 & Returns to scale \\
$\phi$ & 1.5 & Elasticity of substitution between skilled labor and unskilled labor \\
$c^{s}$ & $\{0,50\}$ & Convex adjustment cost of skilled labor \\
$c^{u}$ & 1 & Convex adjustment cost of unskilled labor \\
$\lambda^{s}$ & 1.5 & Multiplicative coefficient for skilled labor wage \\
$\lambda^{u}$ & 1.0 & Multiplicative coefficient for unskilled labor wage \\
$\eta^{s}$ & 0.75 & Sensitivity parameter for skilled labor wage \\
$\eta^{u}$ & 0.75 & Sensitivity parameter for unskilled labor wage \\
Stochastic processes & \\
$\sigma^{X}$ & $0.007 / v 3$ & Conditional volatility of aggregate productivity \\
$\rho^{X}$ & $0.98(1 / 3)$ & Persistence of aggregate productivity \\
$\bar{X}$ & 1.50 & Long-run mean of aggregate productivity \\
$\sigma^{Z}$ & 0.20 & Conditional volatility of firm-specific productivity \\
$\rho^{Z}$ & 0.97 & Persistence of firm-specific productivity \\
$\beta$ & 0.999 & Subjective discount factor \\
$\gamma_{0}$ & 17 & Constant price of risk \\
$\gamma_{1}$ & -1000 & Time varying price of risk \\
\hline \hline
\end{tabular}


Table 2: : Industries with highest and lowest average labor skills

This table presents the top 10 (Panel A) and bottom 10 (Panel B) industries sorted on average labor skill in 2010. Industry average labor skill is measured as the industry-level proportion of workers in Job Index Zones 4 and 5 (Skill, in percentage). An industry is defined at the four-digit NAICS level.

\begin{tabular}{llc}
\hline \hline NAICS & \multicolumn{1}{c}{ Industry } & Skill (\%) \\
\hline & \multicolumn{2}{c}{ Panel A: 10 Industries with Highest Average Skills } \\
\hline 5112 & Software Publishers & 79.8 \\
5415 & Computer Systems Design and Related Services & 77.3 \\
3341 & Computer and Peripheral Equipment Manufacturing & 70.4 \\
5417 & Scientific Research and Development Services & 69.0 \\
5413 & Architectural, Engineering, and Related Services & 62.2 \\
5191 & Other Information Services & 60.6 \\
5414 & Specialized design services & 59.8 \\
6113 & Colleges, Universities, and Professional Schools & 58.3 \\
6112 & Junior Colleges & 57.9 \\
5416 & Management, Scientific, and Technical Consulting Services & 55.9 \\
& & \\
& $\quad$ Panel B: 10 Industries with Lowest Average Skills & 0.1 \\
\hline 7222 & Limited-Service Eating Places & 0.2 \\
7221 & Full-Service Restaurants & 0.2 \\
8121 & Personal care services & 0.3 \\
7224 & Drinking Places (Alcoholic Beverages) & 0.3 \\
4531 & Florists & 0.3 \\
4471 & Gasoline Stations & 0.7 \\
4884 & Support activities for road transportation & 0.8 \\
4481 & Clothing Stores & 0.9 \\
4482 & Shoe Stores & 0.9 \\
5617 & Services to buildings and dwellings & \\
\hline
\end{tabular}


Table 3: : One-Way-Sorted Labor Skill Portfolios

This table reports the average excess returns and characteristics of ten one-way sorted (we report portfolios 1-Low, 5-Mid, and 10-High) on labor skill portfolios (Panel A), and two one-way sorted labor skill portfolios (Panel B). $R_{t+1}^{\text {ew }}$ and $R_{t+1}^{\mathrm{vw}}$ are the average annualized $(\times 1200)$ equal-weighted (ew) and value-weighted ( $\mathrm{vw}$ ), respectively, portfolio excess stock return (in excess of the risk-free rate); $t]$ are heteroscedasticity-and-autocorrelationconsistent $t$-statistics (Newey-West). L-H stands for the low-minus-high hiring portfolio, and the average stock return of this portfolio is the labor skill return premium. The sample is from July 1988 to June 2010.

\begin{tabular}{|c|c|c|c|c|c|c|c|c|c|c|c|}
\hline & $\overline{R_{t+1}^{\mathrm{ew}}}$ & $R_{t+1}^{\mathrm{vw}}$ & $\overline{\mathrm{IK}}$ & $\mathrm{HN}$ & $\Delta$ Sales & $\overline{\text { Lev }}$ & Size & $\mathrm{BM}$ & Wage & $\overline{\mathrm{K} / \mathrm{L}}$ & Skill \\
\hline \multicolumn{12}{|c|}{ Panel A: 10 Labor Skill Portfolios } \\
\hline Low & 5.28 & 5.67 & 0.19 & 0.03 & 5.15 & 0.26 & 4.83 & 0.68 & 0.31 & 3.24 & 0.04 \\
\hline Mid & 12.83 & 7.15 & 0.21 & 0.04 & 7.72 & 0.14 & 5.01 & 0.55 & 0.24 & 3.82 & 0.22 \\
\hline High & 15.13 & 7.95 & 0.38 & 0.07 & 12.26 & 0.05 & 4.53 & 0.43 & 0.43 & 2.98 & 0.51 \\
\hline $\mathrm{L}-\mathrm{H}$ & 9.85 & 2.28 & 0.19 & 0.04 & 7.11 & -0.21 & -0.30 & -0.25 & 0.12 & -0.26 & 0.47 \\
\hline$[\mathrm{t}]$ & 1.73 & 0.41 & & & & & & & & & \\
\hline \multicolumn{12}{|c|}{ Panel B: 2 Labor Skill Portfolios } \\
\hline Low & 8.59 & 6.35 & 0.19 & 0.03 & 5.86 & 0.23 & 5.11 & 0.63 & 0.22 & 3.67 & 0.10 \\
\hline High & 12.14 & 5.27 & 0.25 & 0.04 & 8.55 & 0.12 & 4.87 & 0.50 & 0.33 & 3.62 & 0.32 \\
\hline $\mathrm{L}-\mathrm{H}$ & 3.55 & -1.09 & 0.06 & 0.01 & 2.69 & -0.11 & -0.24 & -0.13 & 0.11 & -0.05 & 0.22 \\
\hline$[\mathrm{t}]$ & 1.34 & -0.60 & & & & & & & & & \\
\hline
\end{tabular}




\section{Table 4: : Labor Skill and the Hiring Return Spread}

This table reports the average excess returns of five one-way sorted on labor hiring rate portfolios across a sample that includes all firms in the economy (top Panel), only firms located in industries with low skilled labor (middle panel), and only in firms located in industries with high skilled labor (bottom panel). We split the firms into low and high skilled industries based on the median value of the industry-level labor skill variable in the cross-section in each year. In addition, the table reports the pricing errors (alpha, $\alpha)$ from the unconditional monthly CAPM regressions applied to the hiring portfolios (value-weighted returns). $R_{t+1}^{e}$ is the average annualized $(\times 1200)$ portfolio excess stock return; $[t]$ are heteroscedasticity-and-autocorrelationconsistent $t$-statistics (Newey-West). L-H stands for the low-minus-high hiring portfolio, and the average stock return of this portfolio is the hiring return spread. The sample is from July 1988 to June 2010.

\begin{tabular}{|c|c|c|c|c|c|c|}
\hline & LLW & 2 & 3 & 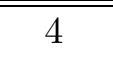 & High & $\overline{\mathrm{L}-\mathrm{H}}$ \\
\hline & \multicolumn{6}{|c|}{ All Firms } \\
\hline$R_{t+1}^{\mathrm{e}}$ & 9.25 & 6.93 & 7.24 & 7.4 & 2.09 & 7.17 \\
\hline$[\mathrm{t}]$ & 2.19 & 2.13 & 2.23 & 1.89 & 0.41 & 2.23 \\
\hline$\alpha$ & 3.19 & 2.01 & 2.12 & 1.28 & -5.36 & 8.55 \\
\hline$[\mathrm{t}]$ & 1.72 & 1.4 & 1.96 & 1.05 & -2.37 & 2.67 \\
\hline \multirow[t]{2}{*}{$\beta^{\mathrm{MKT}}$} & 1.08 & 0.87 & 0.91 & 1.09 & 1.32 & 0.25 \\
\hline & \multicolumn{6}{|c|}{ Low Skill Industries } \\
\hline$R_{t+1}^{\mathrm{e}}$ & 7.95 & 7.43 & 7.45 & 5.23 & 4.28 & 3.67 \\
\hline$[\mathrm{t}]$ & 1.79 & 1.97 & 2.11 & 1.30 & 0.85 & 1.37 \\
\hline$\alpha$ & 1.70 & 2.11 & 2.19 & -0.64 & -2.98 & 4.68 \\
\hline$[\mathrm{t}]$ & 0.80 & 1.10 & 1.47 & -0.39 & -1.36 & 1.73 \\
\hline \multirow[t]{2}{*}{$\beta^{\mathrm{MKT}}$} & 1.11 & 0.95 & 0.93 & 1.04 & 1.29 & 0.18 \\
\hline & \multicolumn{6}{|c|}{ High Skill Industries } \\
\hline$R_{t+1}^{\mathrm{e}}$ & 9.40 & 7.30 & 8.67 & 7.10 & 2.43 & 6.97 \\
\hline$[\mathrm{t}]$ & 2.08 & 2.25 & 2.45 & 1.57 & 0.43 & 1.83 \\
\hline$\alpha$ & 3.25 & 2.39 & 3.12 & 0.47 & -5.40 & 8.65 \\
\hline$[\mathrm{t}]$ & 1.49 & 1.53 & 2.59 & 0.24 & -1.77 & 2.27 \\
\hline$\beta^{\mathrm{MKT}}$ & 1.09 & 0.87 & 0.99 & 1.18 & 1.39 & 0.30 \\
\hline
\end{tabular}


Table 5: : Labor Skill and the Joint Labor Hiring and Investment Return Spreads

This table reports the average excess returns of nine portfolios two-way-sorted on hiring rate (HN) and physical capital investment rate (IK). Panel A reports the results across a sample of firms in low skill labor industries. Panel B reports the results across a sample of firms in high skill labor industries. $R_{t+1}^{e}$ is the average annualized $(\times 1200)$ portfolio-level excess stock return; $[t]$ are heteroscedasticity-and-autocorrelationconsistent $t$-statistics (Newey-West). The sorting on hiring rate is reported across rows Low, Mid, and High, and the sorting on physical capital investment rate is reported across columns Low, Mid, and High. L$\mathrm{H}$ stands for the low-minus-high hiring portfolio (across rows), or the low-minus-high investment portfolio (across columns). Avg Spread reports the average hiring return spread (HN) across the three investment (Low, Mid, High) portfolios), and the average investment return spread (IK) across the three hiring (Low, Mid, High) portfolios. The sample is from July 1988 to June 2010.

\begin{tabular}{|c|c|c|c|c|c|c|c|c|}
\hline \multirow[b]{2}{*}{ Hiring } & \multicolumn{5}{|c|}{ Investment } & & \multicolumn{2}{|c|}{ Avg Spread } \\
\hline & Low & Mid & High & L-H & {$[\mathrm{t}]$} & & $\mathrm{HN}$ & IK \\
\hline & \multicolumn{8}{|c|}{ Low Skill Industries } \\
\hline Low & 7.51 & 8.52 & 5.22 & 2.29 & 0.91 & $\mathrm{R}_{t+1}^{e}$ & 1.58 & 2.0 \\
\hline Mid & 7.45 & 7.31 & 6.50 & 0.95 & 0.36 & {$[\mathrm{t}]$} & 0.96 & 0.83 \\
\hline High & 6.54 & 6.22 & 3.75 & 2.80 & 0.80 & $\alpha$ & 1.90 & 3.55 \\
\hline L-H & 0.97 & 2.30 & 1.48 & 3.77 & 0.97 & {$[\mathrm{t}]$} & 1.12 & 1.56 \\
\hline$[\mathrm{t}]$ & 0.47 & 1.25 & 0.51 & & & & & \\
\hline
\end{tabular}

High Skill Industries

\begin{tabular}{lrrrrllll}
\hline Low & 10.03 & 10.13 & 7.76 & 2.28 & 0.55 & $\mathrm{R}_{t+1}^{e}$ & 4.14 & 3.25 \\
Mid & 7.00 & 9.62 & 6.38 & 0.62 & 0.14 & {$[\mathrm{t}]$} & 2.01 & 0.77 \\
High & 8.39 & 5.56 & 1.56 & 6.84 & 1.26 & $\alpha$ & 4.57 & 6.60 \\
L-H & 1.64 & 4.57 & 6.20 & 8.48 & 1.49 & {$[\mathrm{t}]$} & 2.23 & 1.76 \\
{$[\mathrm{t}]$} & 0.59 & 1.92 & 1.77 & & & & & \\
\hline
\end{tabular}


Table 6: : Pooled OLS Regressions

The table reports the slope coefficients from pooled firm-level ols regressions to predict annual excess stock returns separately across firms in low and high skill industries. The variables used to predict returns: an intercept (not reported), HN, the hiring rate for the fiscal year end in t-1; and IK, the physical investment rate for the fiscal year end in $t-1 . R^{2}$ is adjusted for degrees of freedom. $[t]$ is computed from standard errors clustered by firm and year. To decrease the influence of outliers, the firm-level investment rate is winsorized at the top and bottom $0.5 \%$ in each cross-section. The explanatory variables are standardized to have zero mean and unit standard deviation, so the slope coefficient can be interpreted as the effect on firms' stock return (in percentage, per annum) of a unit standard deviation increase of the explanatory variable. The sample is from 1988 to 2010.

\begin{tabular}{lrrrrrrrr}
\hline \hline & \multicolumn{3}{c}{ Low Skill Industries } & & \multicolumn{3}{c}{ High Skill Industries } \\
\cline { 2 - 3 } \cline { 8 - 9 } & $(1)$ & $(2)$ & $(3)$ & & $(4)$ & \multicolumn{1}{c}{$(5)$} & \multicolumn{1}{c}{$(6)$} \\
\hline $\mathrm{IK}$ & -6.56 & -3.07 & -5.80 & & -8.84 & -3.29 & -7.56 \\
{$[\mathrm{t}]$} & -5.04 & -2.73 & -7.34 & & -2.89 & -2.10 & -4.68 \\
$\mathrm{HN}$ & -2.49 & -1.27 & -2.34 & & -6.47 & -3.56 & -5.39 \\
{$[\mathrm{t}]$} & -2.20 & -1.61 & -3.28 & & -2.18 & -1.89 & -3.74 \\
$\mathrm{R}^{2}$ & 1.41 & 0.32 & 1.29 & & 2.25 & 0.46 & 1.91 \\
\hline Fixed Effects & & & & & & & \\
Firm & Yes & & Yes & & Yes & & Yes \\
Year & & Yes & Yes & & Yes & Yes \\
\hline
\end{tabular}


Figure 1: : Risk Premia and the Hiring Return Spread Across Industries with Different Labor Skills

This figure plots the hiring return spread (in percentage, per annum) across three different calibrations of the model: i) zero adjustment cost in skilled labor $\left(c^{s}=0\right)$; ii) medium adjustment cost in skilled labor $\left(c^{s}=5\right)$; iii) high adjustment cost in skilled labor $\left(c^{s}=50\right)$. The first case corresponds to a low skilled labor industry, whereas the second and the third case correspond to an industry with medium or highly skilled labor, respectively. In total, 100 panels are simulated from each specification of the model, each with 3,600 firms and 1,000 months. The first 400 months are dropped to neutralize the impact of initial conditions. In each panel, we aggregate the monthly quantity variables to the annual frequency. We construct ten portfolios sorted on firms' hiring rates. The hiring return spread is the average return difference between the bottom decile (firms with low hiring rates) and the top decile portfolios (firms with high hiring rates).

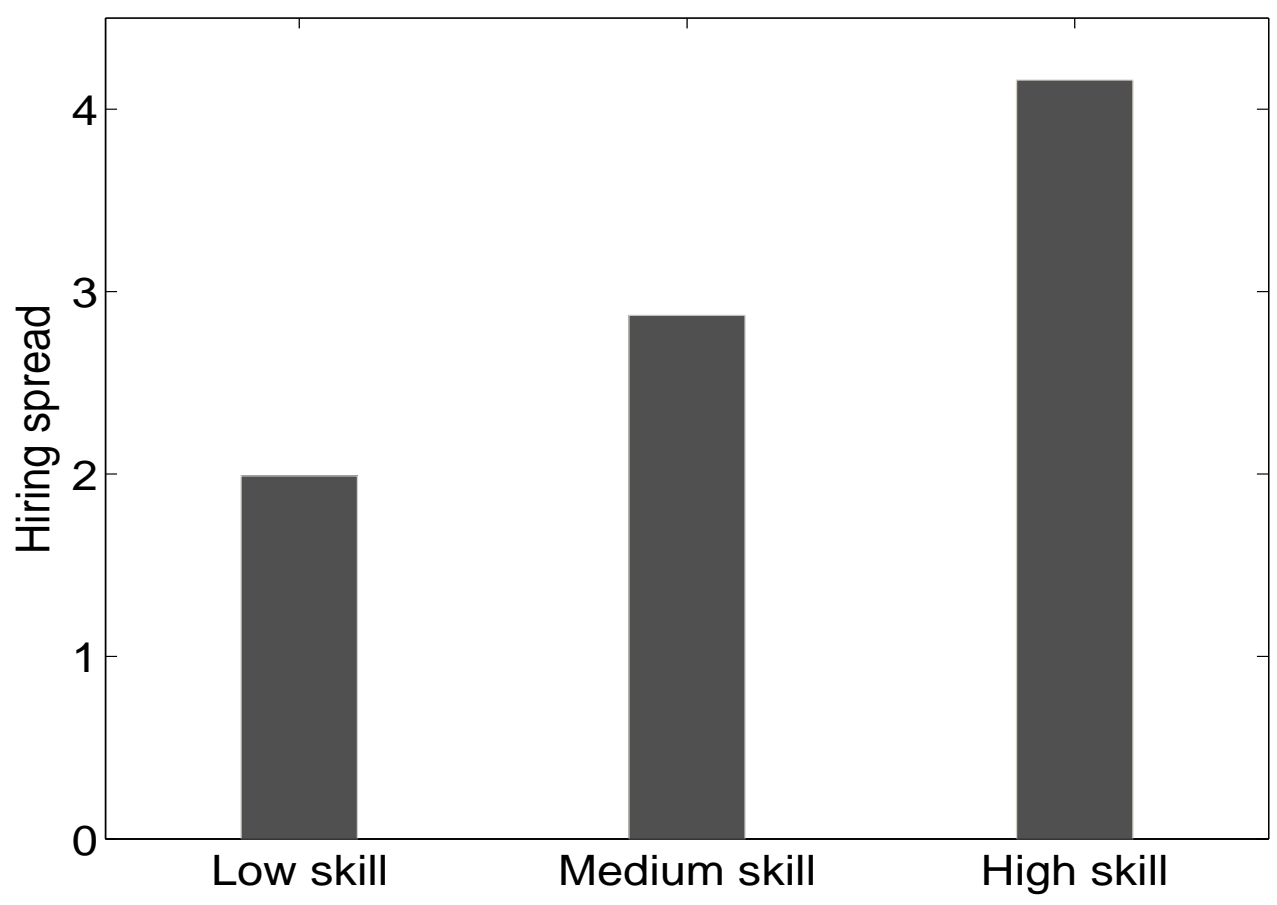


Figure 2: : Labor Skill Return Spread and Firm Size

This figure plots the labor skill return spread (high skill minus low skill) against firm size (ex dividend stock price) across two different calibrations of the model: i) low adjustment cost in skilled labor $\left(c^{s}=5\right)$; ii) high adjustment cost in skilled labor $\left(c^{s}=50\right)$. The first case corresponds to a low skilled labor industry, whereas the second case corresponds to an industry with highly skilled labor. In total, 100 panels are simulated from each specification of the model, each with 3,600 firms and 1,000 months. The first 400 months are dropped to neutralize the impact of initial conditions. In each panel, we aggregate the monthly quantity variables to the annual frequency. We construct ten portfolios sorted on firms' ex dividend stock price and then calculate the return difference between the high skilled and the low skilled cases for three groups of firms: small, medium, and large. Small firms are the bottom decile of the size portfolios, medium firms are the average of the fifth and sixth size portfolios, and large firms are the top decile.

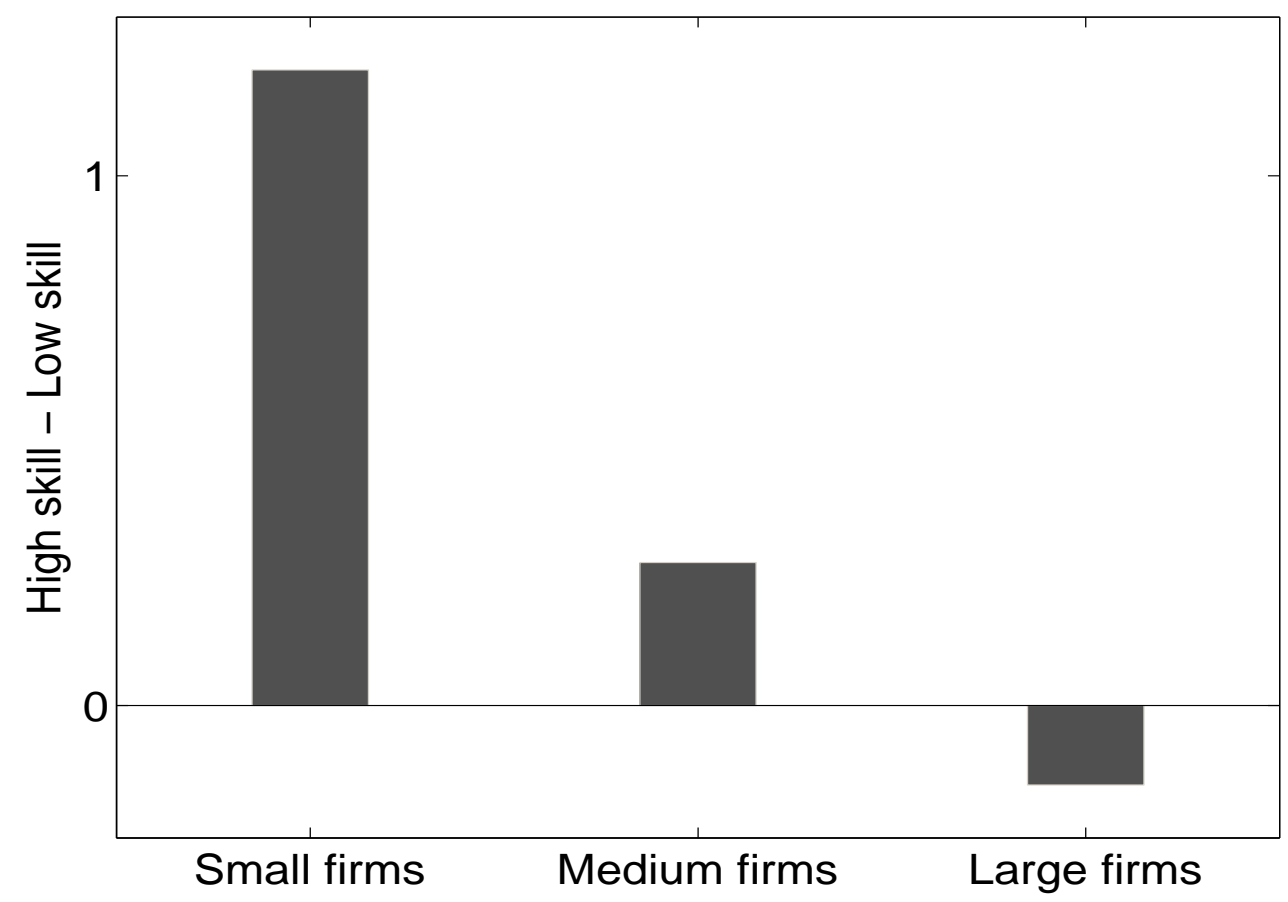

